\title{
SAFETY\&DEFENSE
}

Scientific and Technical Journal ISSN 2450-551X

\section{Hypersonic Weapon as a New Challenge for the Anti-Aircraft Defense Command and Control System}

\author{
Piotr MALINOWSKI \\ Military University of Aviation, Dęblin, Poland; p.malinowski@law.mil.pl, \\ ORCID: 0000-0002-4240-982X
}

DOI: https://doi.org/10.37105/sd.87

\begin{abstract}
The intensification of the air threat resulting from the emergence of hypersonic weapons in the immediate vicinity of Poland has become a significant challenge for the Polish armed forces, including anti-aircraft defense. The capabilities of the new type of weapon determine not only the need to modernize and acquire systems designed to engage aerial targets, but also the command and control systems that control them. Due to the nature and the limited scope of the article, the deliberations presented in it are generalized results of a research on the scale of the threat posed by hypersonic weapons in the airspace and the need to modernize anti-aircraft defense command and control subsystems, which may be involved in combating them as part of the national air defense system. The presented conclusions also concern the problems of multiplying the current level of automation of the command and control subsystem. This is related to the need for the effectiveness of the military decisionmaking process as well as uninterrupted and efficient cooperation with the national and allied elements of the air reconnaissance and air defense assets subsystems, including the components of missile defense, which is predestined to engage hypersonic weapons.
\end{abstract}

Keywords: military security, hypersonic weapons, anti-aircraft defense, C2 system

\section{Introduction}

The advent of the era of hypersonic air threats in tactical operations is redefining the requirements for the entire anti-aircraft defense system, including its command and control subsystem. Although the idea of creating a weapon capable of immediate reaction, of large range, is not new, still its embodiment in the form of a Russian hypersonic weapon is a significant transformation 
of the threats that determine the necessary transformation of the domestic anti-aircraft defense potential.

The desire to intensify the automation of anti-aircraft defense command and control processes results from the complexity of effective combat against aerial targets that are so difficult to engage. It is also a requirement for the dynamization of operations on the contemporary battlefield where not only hypersonic weapons pose significant air threats. However, its current introduction into the strike assets arsenal of several armies around the world reveals not only the scale of the new threat. It also determines, as shown by the conducted research, an urgent need to achieve an appropriate level of defense against this type of air threats, which will be also influenced by the efficient functioning of the command and control subsystems.

This article contains considerations and conclusions, the purpose of which is to present the characteristics and capabilities of hypersonic weapons, particularly emphasizing the armament of the Russian Federation, as well as the impact of these weapons on the modernization and automation of the antiaircraft defense command and control subsystem. Therefore, the author focused on solving the following research problem: How do the capabilities of hypersonic weapons affect the needs of modernization and automation of the anti-aircraft defense command and control subsystem? A mixed research method, based on the elements of text and literature exploratory research (analysis), simulation of anti-aircraft defense combat capabilities, experiment during military exercises was used to solve the indicated problem during the research, the generalized results of which are included in the article.

\section{Hypersonic weapons as an air threat}

For around two decades, several countries around the world (GMTFF, 2019) including Russia, were working towards primarily using hypersonic technology in the ballistic missiles weapon segment, boostglide vehicles, and cruise missiles. The emergence of military strike systems in the airspace that are capable of delivering precise strikes at speeds several times the speed of sound is a significant challenge for the entire air defense system, including anti-aircraft defense. Currently, such weapons are classified as supersonic or hypersonic. The first group includes missiles which fly above Mach 1 . They are generally regarded as flying between Mach 1 and Mach 5, about 1,000 to $5,000 \mathrm{~km} / \mathrm{h}$ (Speier, 2017, p. 2). Whereas the term hypersonic weapon is generally understood to refer to the ones that fly within the atmosphere at speeds above Mach 5 (five times the speed of sound), or above 6,100 $\mathrm{km}$ per hour. One focus of military interest is hypersonic missiles that can travel at approximately 5,000 to $25,000 \mathrm{~km}$ per hour (or between 1.4 and 7 meters per second) (Speier, 2017, p. 2) - up to 25 times faster than a standard airliner. Additionally hypersonic weapons refer to weapons that not only travel faster than Mach 5 but also have the capability to maneuver during the entire flight.

New hypersonic systems currently have two primary sub-varieties: hypersonic glide vehicles (HGVs), and hypersonic cruise missiles. The first sub-variety, hypersonic glide vehicles are typically launched by rockets into the upper atmosphere. After disengaging from the carrier missile, the hypersonic vehicle lowers its altitude and continues to fly to its target by itself. They are released at altitudes that can vary from around $50 \mathrm{~km}$ to higher than $100 \mathrm{~km}$ and glide to their targets by skipping along the upper atmosphere. HGVs have a range comparable to ballistic missiles but they fly at a lower altitude, and a negligible portion of their flight path follows a ballistic trajectory. This results in the time between detection by ground-based sensors and impact being shorter compared to a ballistic missile's re-entry vehicle (Brehm, Weeler, 2019, p. 2). The HGVs are carried to the upper layers of the atmosphere 
by rocket missiles, which give them an appropriate initial velocity.

The second sub-variety are hypersonic cruise missiles (HCMs). Hypersonic missiles typically operate using air-breathing supersonic combustion ramjet (scramjet) engines to accelerate and maintain missile velocity. A scramjet usually begins operating at Mach 4 or Mach 5 . Therefore, a hypersonic cruise missile must first be accelerated to Mach 4 or Mach 5 by other means, such as rocket engines (Hruby, 2019, p. 18).

HCMs could be ground-, air- or shiplaunched and would likely fly at an altitude of 20 to $30 \mathrm{~km}$, beyond the reach of most current air-to-surface missile defence systems (Brehm, Weeler, 2019, p.2). The principal advantages of an HCM would be its speed and maneuverability. These cruise missiles are difficult to defend against because of their unpredictable trajectories. Both hypersonic types of weapons can carry a nuclear warhead, a conventional explosive warhead, or no warhead at all, instead relying on sheer kinetic force to destroy its target. There are many other potential types of hypersonic weapon being developed. These include more complex missile systems, manned and unmanned reusable air vehicles, and space launch systems (Speier, 2017, p. 4).

The threat of using hypersonic weapons in an armed conflict, resulting from one party's possession of these is a factor that creates a completely new dimension of air threat. This is because hypersonic weapons combine the speed of a ballistic missile with the maneuvering capabilities of a cruise missile. In the opinion of the US military analysts "while the designed speed of the hypersonic missile is faster than that of sound, its advantage lies in its enhanced maneuverability and smooth flight path, which is much harder to track than that of traditional missiles" (Osborn, 2017). It is also a weapon which is specifically designed for increased survivability against modern ballistic missile defense systems. Additionally, for users, hypersonic weapons have the advantage of being the type of weapon whose "accuracy minimizes the risk of collateral damage, that pose no risk to aircrews, are unstoppable and phenomenally accurate, can yield an impact equal to five to ten tons of high explosive with no warhead at all yet be capable of delivering a nuclear bomb, and can reach nearly every coordinate on the surface of the earth within 30 minutes" (Simon, 2020). For this reason, it is recognized as a threat that can change the perception of the implementation of air strikes and the way of achieving strategic goals of military operations. This is influenced by the possibilities of the hypersonic weapons due to which "they are able to evade and conceal their precise targets from defenses until just seconds before impact. This leaves targeted states with almost no time to respond" (Speier, 2018).

Taking into account the geostrategic location of Poland, after analyzing the development trends of hypersonic weapons, it can be concluded that the most serious air threat related to the use of this type of weapon is likely from the Russian systems of this weapon. It may result from the use of both hypersonic glide vehicles (HGVs) and hypersonic cruise missiles (HCMs) owned by the Russian Federation.

The first strategic type of Russian hypersonic weapon is the Avangard (Vanguard) hypersonic boost-glide vehicle, which is part of an intercontinental ballistic missile (ICBM) missile complex equipped with a hypersonic glide warhead (Trimble, 2019, p. 20). Each ICBM is armed with one hypersonic boost-glide warhead. Avangard is carried to its suborbital apogee of around 100 $\mathrm{km}$ by a ballistic missile. Once boosted to its suborbital apogee, the glide vehicle separates from its rocket. It then cruises down towards its target through the atmosphere and can reach speeds of up to Mach 20 (6.28 $\mathrm{km} / \mathrm{s}$ ) and can maneuver (MDPA, 2019). Therefore, Avangard's trajectory is unpredictable and makes intercept attempts difficult after its boost phase.

Avangard, a hypersonic glider previously known as 'Project 4202' or 'Yu-71', or the Aerobalistic Hypersonic Warhead has been tested multiple times since February 2015 (Sputnik, 2016). Currently, warheads of this type are mounted on intercontinental 
ballistic missiles UR-10oNUTTH (SS-19 Stiletto). The first regiment of ICBMs, armed with the newest, hypersonic Avangard system, achieved combat readiness in December 2019 (TVN24 BIS, 2019). By the end of 2027, that regiment and one other are to have six Avangard systems each, for a total of 12 systems (GMTFF, 2019). Ultimately , the hypersonic boost-glide vehicles (HGVs) Avangard are intended to be mounted as an element of the Russia's RS-28 Sarmat (SS-X30) - the state-of-the-art heavy liquid-propelled ICBM which are currently being developed for the Russian army.

Another type of Russian hypersonic weapon is The Kinzhal (Dagger) system, which is essentially a combination of a $\mathrm{KH}$ 47M2 heavy hypersonic rocket and a MiG$31 \mathrm{~K}$ fighter jet or $\mathrm{Tu}-22 \mathrm{M}_{3}$ carrier bomber (Global Security, n.d.). It is planned that it will be also carried by a new Su-57 stealthy multi-role fighters (Military Today 2020a, n.d.). The aeroballistics hypersonic missile Kinzhal (Dagger) has a "quasi-ballistic" flight path at altitudes from 35 to $50-80$ or more kilometers. The Kinzhal (Dagger) is a hypersonic missile, which, according to Russian data, has a range of about 1,500 to $2,000 \mathrm{~km}$ (Palowski, 2020b). It is an airlaunched ballistic missile (ALBM) (MDP, 2019) carried by a combat aircraft with speeds above $5 \mathrm{Ma}$ (according to some sources, even $10 \mathrm{Ma}$ ) at certain stages of flight, on a similar basis as ballistic missiles launched from the ground. During the flight, the missile maintains the ability to maneuver and correct its trajectory. According to Russian doctrine, it is capable of carrying both conventional warheads (weighing around $480 \mathrm{~kg}$ ) and nuclear charges as well.

The Kinzhal (Dagger) missile has a similar design to the Iskander-M missiles. However, its launch not from the ground, but from an aircraft flying at more than twice the speed of sound, in addition to high altitude, makes it a much greater air threat than the Iskander missile. Such a missile launched from an airplane does not have to use energy to take off from the ground, thus it has greater spatial possibilities in terms of velocity and range.
The KH-47M2 Kinzhal (Dagger) missile introduced in 2018 may therefore be a very dangerous strike system, used to blackmail and "cut off" support for NATO's eastern flank far ahead of the potential conflict area, or to perform quick, hard-to-repel strikes on Poland or the Baltic countries (Palowski, 2020a). It results from the possibilities of this armament, presented in Figure 1.

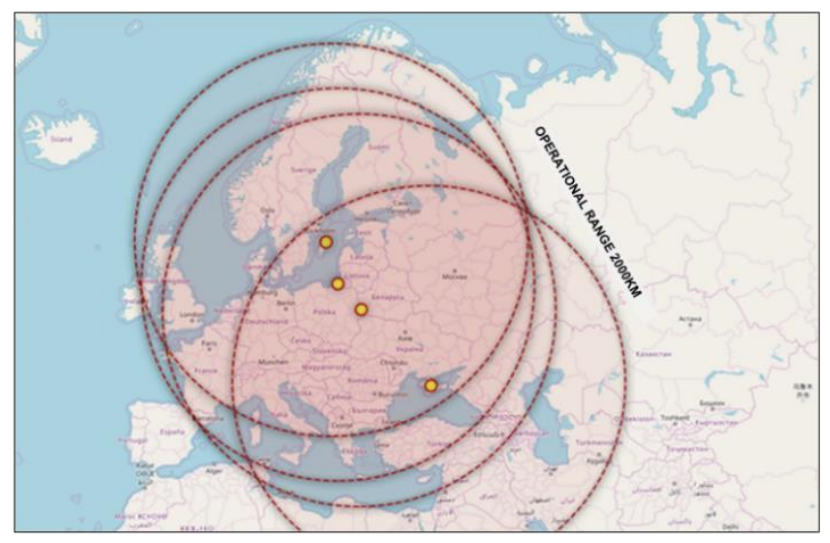

Figure 1. The potential operational range of The Kh-47M2 Kinzhal (Dagger). Adopted from: "Hipersoniczny wyścig potęg [ANALIZA]" by M. Dąbrowski. Copyright 2020 by Defence24 (Dąbrowski, 2020).

An air-launched KH-47M2 Kinzhal hypersonic missile traveling at Mach 10 could hit Sofia, Bulgaria, about $2000 \mathrm{~km}$ to the south, in 11 minutes from the Gulf of Finland. Re-orienting the firing line to Russia's western borders, a Kinzhal could reach London, Paris, or Rome equally quickly. To put it another way, hypersonic weapons mean that a hypothetical target $2000 \mathrm{~km}$ away has the same potential of being threatened as those within roughly $150 \mathrm{~km}$ of a subsonic cruise missile. On the other hand, the Mach 20 Avangard expands the threat umbrella to cover ranges reportedly in excess of 6000 $\mathrm{km}$ with a flight time of around 20 minutes (Cummings, 2019). Therefore, only those systems that are capable of destroying maneuvering ballistic missiles may be able to combat such threats as the KH-47M2 Kinzhal (Dagger), provided that the threat is detected and classified early and can be tracked by fire control systems.

The multi-purpose operational/tactical hypersonic cruise missile 3M22 Tsirkon (Global Security, 2019) has also been 
developed in Russia. HCM Zircon is mostly an antiship missile, but can also hit ground targets (Vavasseur, 2020). It will be used for arming, among others, Kirov cruisers, missile frigates, Husky ANNs and modified Tu$160 \mathrm{M}$ bombers. During test shooting, this $\mathrm{HCM}$ achieved a range of over $400 \mathrm{~km}$ and a speed corresponding to $5 \div 6 \mathrm{Ma}$ (Dąbrowski, 2020), although the Russians indicate that that it can reach speeds of approximately Mach 9 and strike a target of more than $1,000 \mathrm{~km}$ away (SS-N- 33, 2019). This speed is achieved by a solid-fueled first phase, followed by a scramjet second phase. At the end of 2019, HCM Zircon was launched for the first time from a warship (Defense World, 2019). Although it has not yet been officially confirmed, this missile, in addition to the conventional variants, can be equipped with a nuclear warhead, similar to the American Tomahawk sea launched cruise missile.

Another Russian weapon that only partially uses hypersonic speeds is the Iskander system. Its missiles at the initial stretch of the trajectory, the curve of which is not ballistic and difficult to predict, develop a speed of $2,100 \mathrm{~m} / \mathrm{s}$ (OAS, 2016). Additionally, these missiles are controlled along the entire flight path. One of the versions of these missiles, designated as $9 \mathrm{M} 723-1$, was used to develop the high-precision hypersonic missile KH-47M2 Kinzhal (Dagger) (Global Security, 2020). On the other hand, newer versions of the Iskander system weapons, which are cruise missiles, have lower speeds, but can maneuver around the entire flight path. Currently, a new type of cruise missile 9M729 (MDF, 2020; Military Today, 2020b) has been introduced into combat use in 2017, the range of which can be up to 2,500 $\mathrm{km}$ (Military Today, 2020b). According to Russian sources, the Iskander system is capable of eliminating such targets as multiple rocket launchers, long-range artillery, command and communication centers and planes and helicopters on the ground (TASS, 2017). The equipment of this system will be further modernized, as reported by the Russians, who indicate: "We are going ahead with further research and development to create new missiles for the Iskander system.
(...) Now we have seven types of missiles, or possibly more" (TASS, 2017).

Russia, however, does not stop at increasing the potential of the three indicated models, but having extensive experience in the field of missile technology, it is preparing further improved solutions for hypersonic weapons launched from the air, water and ground for various purposes. At the same time, it implements and constructs defensive weapon systems prepared to combat the enemy's hypersonic weapons.

\section{Determinants of the operation of the anti-aircraft defense com- mand and control subsystem}

The operation of the command and control subsystem is crucial for achieving the goal of anti-aircraft combat and performing the tasks of the anti-aircraft defense system. Its effect, ensuring optimal information support and the reactions of other elements of the system, especially the reconnaissance subsystem and the fire subsystem, determines the speed of reaction to changes in the air situation and emerging air threats. The functioning of this subsystem also determines the efficiency of cooperation with other elements of air defense. It also influences the outcome of the fight against the means of air attack that threaten protected military facilities and groups of troops during tactical operations, as well as self-defense (self-protection).

A command and control subsystem, integrating $\mathrm{C}_{2}$ organization, $\mathrm{C}_{2}$ process and $\mathrm{C} 2$ facilities within itself, should meet three basic requirements, i.e. ensure the implementation of goals, be structurally stable, facilitate adaptation to changes in external conditions (Kręcikij, and Wołejszo, 2007, p. 64). Its functionality, in all conditions of anti-aircraft defense system operation, ensures compliance with several basic criteria, including: 
- Adaptability to the high dynamics of activities in the airspace.

- Mobility combined with the ability to direct the actions of subordinate forces.

- Multifunctionality related to the needs of cooperation with other subsystems and contractors of tasks as well as elements supplying information.

- Operational selectivity aimed at the coordination of various activities necessary for the combat effectiveness and security of the air defense system.

- Centralization of planning and decentralization of task execution.

- Modularity that guarantees reconfiguration necessary to perform new tasks.

- Resistance to various disturbances in functioning (Rajchel, and Załęski, 2011, p. 235).

At the same time, the operation of the command and control system is to ensure flexibility that allows the commander to operate freely and to react in various unforeseen situations. It is also to guarantee efficiency, i.e. such a method of operation that allows to achieve better results with the same resources and efficiency expressed in the possibility of quick decision-making and bringing them to contractors while maintaining the requirement of secrecy (PP, 2009, p. 318-319). On the other hand, the requirements to achieve an appropriate level of compatibility and interoperability in the course of cooperation in the Alliance structures mean that the anti-aircraft defense command and control system must have the ability to cooperate with other allied or coalition air defense command systems.

Significant requirements for the anti-aircraft defense command and control system are also related to its operational efficiency during the implementation of tasks, expressed in the speed of the information-decision cycle. This efficiency, defined by the time dependence (OP, 1996, p. 60), presented below, is a set of indicators of the time capabilities of the command and control and fire systems and a sine qua non condition for engaging aerial targets.
$\mathrm{Tdc} \geq \mathrm{To}+\mathrm{Td}+\mathrm{Tz}$

where:

- Tdc - target arrival time (from the moment of detecting the source of the air attack to its arrival to the border of the aerial target engage);

- To - delay of information on the basis of which the decision is made to engage an aerial target);

- Td - decision making time and handing it over to executors;

- $\mathrm{Tz}$ - the time from the moment of receiving the task by the anti-aircraft defense fire assets until the destruction of the aerial target on the assigned task execution area).

The time indicators related to the operation of the command and control system are the components of the fire mission completion time, which can be significantly reduced by the proper organization of the system and its equipment.

The anti-aircraft defense command and control system is to meet the presented criteria and requirements both in tactical command (combat control) and during fire command (fire control), regardless of the type of air threat that appears in the airspace. This is especially important in fire control, during which, thanks to the efficient cooperation of the anti-aircraft defense subsystems, as well as the cooperation with the air defense system, an effective combat against the assets of air attack of the potential enemy is ensured.

\section{The influence of hypersonic weap- ons on the modernization of the command system}

In terms of effectiveness of the hypersonic weapons, the speed and altitude at which these vehicles fly significantly challenge an adversary's ability to detect, track, target and engage (Raytheon Missiles \& Defense, 2020). Interception of a hypersonic missile or a warhead requires detection, 
tracking with high precision, calculating the flight trajectory, accurate forecasts of its further heading and programming of anti-missiles. The later the target of an enemy's hypersonic weapon is detected, the less time is left for an effective response. For example, if the opponent plans to strike the target within a 1,000-km range, a hypersonic missile traveling at 10 Ma can cover that distance and reduce the response time to about six minutes. In addition, in the case of hypersonic missiles, apart from high speed, we also deal with maneuverability, which makes it very difficult or virtually impossible to predict the exact direction of the flight. At the same time, the closer to the potential target of the attack, i.e. the protected object, the predictability of the projectile's flight path increases, but the time to react significantly decreases.

Due to the fact that the scope of anti-aircraft defense, depending on the scale and type of aerial threat, may be different, it cannot be ruled out that in the near future it may be extended to combat this type of weapon due to a significant increase in the potential enemy's arsenal of hypersonic weapons. All the more so because, according to some experts, hypersonic weapons function more effectively against threats from strategic antimissile systems than from operational-tactical ones (Dąbrowski, 2020). This approach is also confirmed by theoretical assumptions and modern hardware solutions indicating that the anti-aircraft defense goes beyond the fight against enemy aviation and extends the scope of tasks to engage ballistic and winged missiles, and even "ground-toground" missiles (PP, 2009, p. 172). However, in the opinion of Simon Steven, analyst at the Quincy Institute, "No existing defenses can stop such weapons" (Simon, 2020), which means that the currently functioning anti-aircraft defense systems must undergo deep modernization and reorganization to meet the challenge of the emergence of hypersonic weapons as an air threat to sheltered objects.

Although, as indicated by a number of studies (Radomyski, 2015, p. 117), the quantitative and qualitative potential of anti- aircraft missile systems and reconnaissance measures as well as the importance of the command subsystem should not be overlooked, in the first place. Its development, focused on the modernization or acquisition of new automated elements, in general is to ensure the reception, selection, analysis and extrapolation of information from superior command and control systems and autonomous and cooperating sources of reconnaissance. The need to improve the command and control system in terms of the speed of these actions is significantly determined by the multiplied possibilities of hypersonic weapons. Meeting the time requirements for the operation of the command system requires a significant shortening of automated analyzes and forecasts as well as the visualization of results and the selective acquisition of reliable and timely information enabling making optimal decisions about opening fire. A similar increase in efficiency should take place in the way of delegating tasks to their contractors, which is supposed to significantly minimize the time needed to make a decision and transfer it to executors $(T d)$. At the same time, one should be aware that the last variable, which is the time of mission execution by anti-aircraft fire assets $(\mathrm{Tz})$, has a constant value which cannot be reduced without replacement with more efficient anti-aircraft defense assets. The functioning of command and systems in the era of hypersonic weapons should additionally, based on increased automation, reduce the basic advantages of this weapon, resulting from its speed and difficulties in predicting the flight trajectory, i.e. minimizing the information delay time ( $\mathrm{To}$ ) also thanks to cooperation with various allied, including space, sources of reconnaissance.

The transformations of the anti-aircraft defense command and control system in the perspective of several years are unlikely to eliminate the human factor from the process of making decisions to fire. However, they are to optimize solutions and accelerate their creation based on a number of available data and incoming information, so as to significantly support the action of the decision maker. In perspective, however, it should be 
assumed that due to the significant increase in the speed of some hypersonic strike systems, it is likely in the next generations of anti-aircraft defense command and control systems that the decision-maker will be replaced by artificial intelligence in the process of making decisions to fire.

The increased risk of using hypersonic weapons by a potential aggressor due to the significantly limited reaction time also forces, in addition to the applied decentralization of command and control, a change in the way of making decisions about the use of anti-aircraft defense assets. The transformation of the anti-aircraft defense command and control system related to the decisions made is to guarantee the performance of all the most labor-consuming and complex analytical activities related to the features of the facilities being the subject of the decision-making process. Then, supporting the decision maker is to guarantee the generation of acceptable course of action and indication of optimal course of action among them, which will enable a rational decision. This applies in particular to analyzes related to the possible directions of a potential enemy's attacks, anti-aircraft fire assets formation planning and the distribution of tasks to sub-units.

The anti-aircraft defense command and control system in the face of the threat of combat troops and military facilities, such as hypersonic weapons, should under all conditions play the role of an efficient and resistant to interference integrator of complex radiolocation and reconnaissance systems as well as anti-aircraft fire assets. Its operation is to ensure the effective creation of a multilayer system of protection against air attacks. At the same time, it is to guarantee efficient cooperation with anti-missile defense systems, which are and will continue to be the main executors of the missions of engaging hypersonic weapons of a potential enemy.

\section{Conclusion}

Highly maneuverable (in terms of heading and altitude) and non-ballistic hypersonic systems can be a difficult target for the currently used anti-missile defense systems and anti-aircraft defense systems cooperating with them. Although future strategic and operational anti-missile systems are indicated as defensive systems against hypersonic weapons, the participation of the antiaircraft defense system in this project may increase in the future. Therefore, the main direction of the development of the anti-aircraft defense command and control subsystem, which was initiated by the LOWCZA and REGA systems, is the further development of cooperation with other command and control and reconnaissance systems and reducing to a minimum the time needed for detailed analyzes and assessment of information necessary to optimize the planning of activities, as well as accelerate the decisionaction cycle and ensuring higher-quality decisions to effectively engage aerial targets.

The facts collected in the course of the research show that the anti-aircraft defense command and control system is facing another challenge which is also its integration with the IBCS (Integrated Air and Missile Defense Battle Command System) providing reciprocal exchange of information with an accuracy sufficient to direct the anti-aircraft fire assets of both systems. The requirement for modernization or a new generation of the anti-aircraft defense command and control subsystem is also the integration and backward compatibility with all elements of the national anti-aircraft defense system (identification and control of anti-aircraft fire assets of all types of armed forces), as well as a multichannel function of higher level than before enabling simultaneous engaging of a larger number of aerial targets. Finally, one should not forget about the issue of mobility, which allows for accompanying combat forces, and modularity ensuring the substitutability of the elements of the anti-aircraft defense command and control system. 
While summarizing the presented considerations, however, it should be kept in mind that in the short term, mainly for economic reasons, it will be necessary to make an inevitable choice what kind of anti-aircraft defense command and control system capability to introduce or modernize in the first place. On the other hand, in the next few years, it seems necessary to start work on the successors of the anti-aircraft defense command and control systems used so far, i.e. a new generation of them capable of comprehensive cooperation with other air defense command systems and various reconnaissance sensors, as well as conducting autonomous or dispersed actions against advanced air threats.

\section{Acknowledgement}

This article is an outcome of the research project "Automation of air defense's information and decision making processes in the modelled environment of air threat to armed forces and critical infrastructure objects" project, No GB/5/2018/209/2018/DA funded by the Polish Ministry of National Defense in 2018 - 2022.

\section{References}

1. Brehm, M., and de Courcy Wheeler, A. (2019). Hypersonic Weapons. Article36. Retrieved from https://www.researchgate.net/publication/334050433_Hypersonic_Weapons, 15.06.2020.

2. Cummings, A. (2019). Hypersonic weapons: Tactical uses and strategic goals. War on the Rocks. Retrieved from https://warontherocks.com/2019/11/hypersonicweapons-tactical-uses-and-strategicgoals/, 15.06.2020.
3. Dąbrowski, M. (2020). Hipersoniczny wyścig potęg [ANALIZA]. Defence24.pl, April 2O, 2019. Retrieved from https://www.defence24.pl/hipersoniczny-wyscig-poteg-analiza, o8.06.2020.

4. Defense World (2019). Russia Likely to Launch Zircon Hypersonic Rocket from a Warship by Yearend. DefenseWorld.net, March 14, 2019. Retrieved from https://www.defenseworld.net/news/24458/Russia_Likely_to_Launch_Zircon_Hypersonic_Rocket_from_a_Warship_by_Yearend\#.X3MiZzbVI2w, 18.06.2020.

5. Global Security (2019). SS-N-33: T3K22 Zircon/Tsircon/3M22 rocket. GlobalSecurity.org. Available online https://www.globalsecurity.org/military/world/russia/zircon.htm, 15.06.2020.

6. Global Security (2020). 9M730 Knizhal - Dagger / Product 75 / Product 715. Available online https://www.globalsecurity.org/wmd/world/russia/9m730.htm, 15.06.2020.

7. Hruby, J. (2019). Russia's New Nuclear Weapon Delivery Systems: An OpenSource Technical Review. Nuclear Threat Initiative. Retrieved from https://media.nti.org/pdfs/NTIHruby_FINAL.PDF, 18.06.2020.

8. Kręcikij, J., and Wołejszo, J. (Eds.) (2007). Podstawy dowodzenia. Warszawa: Wyd. AON.

9. MDF [Missile Defense Project] (2018). Kinzhal. Missile Threat. Center for Strategic and International Studies, March 27, last modified June 23, 2020. Retrieved from https://missilethreat.csis.org/missile/kinzhal/, 24.06.2020.

10. MDF [Missile Defense Project] (2019). Avangard. Missile Threat. Center for Strategic and International Studies, January 3, last modified June 23, 2020. Retrieved from https://missilethreat.csis.org/missile/avangard/, 24.06.2020. 
11. MDF [Missile Defense Project] (202O). SSC-8 (9M729). Missile Threat. Center for Strategic and International Studies, October 23, 2018, last modified June 30, 2020. Retrieved from https://missilethreat.csis.org/missile/ssc-8-novator-9m729/, 08.06.2020.

12. Military Today (2020a). Kh-47M2 Kinzhal: Air-launched ballistic missile. Available online http://www.militarytoday.com/missiles/kh_47m2_kinzhal.htm, 08.06.2020.

13. Military Today (2020b). SSC-8: Longrange cruise missile system. Available online http://www.military-today.com/missiles/ssc_x_8.htm, o8.06.2020.

14. OAS [Ośrodek Analiz Strategicznych] (2016). Rosyjskie rakiety balistyczne zagrożeniem dla NATO [Raport]. Defence24.pl, August 24, 2016. Retrieved from https://www.defence24.pl/rosyjskie-rakiety-balistyczne-zagrozeniemdla-nato-raport, 23.12.2020.

15. OP [Obrona powietrzna] (1996). Warszawa: Wyd. AON.

16. Osborn, K. (2017). Hypersonic Weapons: Everything You Need to Know About the Ultimate Weapon. The $\mathrm{Na}$ tional Interest, July 22, 2017. Retrieved from online https://nationalinterest.org/blog/the-buzz/hypersonicweapons-everything-you-need-knowabout-the-21637, 08.06.2020.

17. Palowski, J. (20201). „Hipersoniczny” Kindżał zagrożeniem dla Europy [OPINIA] (202Oa). Defence24.pl, May 10, 2018. Retrieved from https://www.defence24.pl/hipersoniczny-kindzalzagrozeniem-dla-europy-opinia, 08.06.2020.

18. Palowski, J. (202b). Rakiety Kindżał i Kalibr strzelają nad Morzem Czarnym. Defence24.pl, January 1O, 2020. Retrieved from https://www.defence24.pl/rakiety-kindzal-i-kalibrstrzelaja-nad-morzem-czarnym, 08.06.2020.

19. PP [Podręcznik przeciwlotnika] (2009). Warszawa: Wyd. AON.
20. Radomyski, A. (Ed.) (2015). Podstawy obrony powietrznej. Warszawa: Wyd. AON.

21. Rajchel, J., Załęski, K. (2011). Dowodzenie siłami powietrznymi, aspekt narodowy i sojuszniczy: Uwarunkowania, Tendencje i kierunki zmian. Zeszyty Naukowe AMW, 3(186), 229-250.

22. Raytheon Missiles \& Defense (2020). Hypersonics. Available online https://www.raytheonmissilesanddefense.com/capabilities/hypersonics, 15.06.2020.

23. Simon, S. (2020). Hypersonic Missiles Are a Game Changer. The New York Times, January 2, 202O. Retrieved from https://www.nytimes.com/2020/01/02/opinion/hypersonic-missiles.html, 15.06.2020.

24. Speier, R.H. (2018). Hypersonic Missiles: A New Proliferation Challenge. Georgetown Journal of International Affairs, March 26, 2018. Retrieved from https://www.georgetownjournalofinternationalaffairs.org/onlineedition/2018/3/26/hypersonic-missiles-a-new-proliferation-challenge, 15.06.2020.

25. Speier, R.H., et al. (2017). Hypersonic Missile Nonproliferation: Hindering the Spread of a New Class of Weapons. Rand Corporation. Retrieved from https://www.rand.org/pubs/research_reports/RR2137.html, 08.06.2020.

26. Sputnik (2016). Russian Top Secret Hypersonic Glider Can Penetrate Any Missile Defense. Sputnik, June 11, 2016. Retrieved from https://sputniknews.com/politics/201606111041185729-russia-hypersonic-glider/, 18.06.2020.

27. TASS (2017). Iskander-M system gets new types of missiles - manufacturer. TASS, September, 14, 2017. Available online https://tass.com/defense/965611, 15.06.2020.

28. Trimble, S.A. (2019). Hypersonic Sputnik? Aviation Week, January 14-27, pp. 20-21. Retrieved from 
https://archive.aviationweek.com/issue/20190114, 15.06.2020.

29. TVN24 BIS (2019). Odpowiednia i symetryczna odpowiedź: Rosyjskie awangardy w gotowości bojowej. TVN24 BIS, December 27, 2019. Available online https://tvn24.pl/swiat/rosja-systempociskow-hipersonicznych-awangardosiagnal-gotowosc-bojowa-ra9960312857102, 08.06.2020.

30. Vavasseur, X. (2020). Analysis: Russia's Tsirkon Hypersonic Missile Trials Enter Final Stage - Part 2. Naval News, March 3, 2020. Retrieved from https://www.navalnews.com/navalnews/2020/o3/analysis-russias-tsirkon-hypersonic-missile-trials-enter-final-stage-part-2/, 08.06.2020. 